\title{
Prevalence study of brucellosis among high-risk people in xinjiang region, China
}

\author{
Guoqiu Wu ${ }^{1 *}$, Chengxin Yang ${ }^{1,2}$, jing Liं ${ }^{2}$ Nannan Liü ${ }^{3}$, Wenhai Yao ${ }^{2}$, Rui Zhang ${ }^{2}$ and Zhiqiang Lin ${ }^{2}$ \\ *Correspondence: nationball@163.com \\ ${ }^{1}$ Center of clinical laboratory medicine of Zhongda Hospital, Southeast University, Nanjing 210009, China. \\ 2Department of laboratory, Infectious Disease Hospital of Xinjiang Uygur Autonomous Region, Urumqi, 830013, China. \\ ${ }^{3}$ Medical School of Southeast University, Nanjing 210009, China.
}

\begin{abstract}
Background: Brucellosis was a zoonotic disease causing serious public health and economic problems.

Methods: Total 2,648 samples were collected between July 2011 and August 2012 from high-risk individuals, who were outpatients at Infectious Disease Hospital of Xinjiang Uygur Autonomous Region. The diagnosis was based upon clinical symptoms and serological or bacteriological test.

Results: 1080 individuals (40.8\%) were diagnosed as having been infected with brucellosis. The positive rate of brucellosis diagnosis was correlated with gender, ethnic group and clinical symptoms. All isolates from blood culture were identified as Brucella melitensis biotype 3 .

Conclusions: High prevalence of brucellosis exists in Xinjiang, China. An improved healthcare system and preventive measures is needed to minimize the infection of brucellosis.
\end{abstract}

Keywords: Brucellosis, high-risk groups, prevalence, serological test, bacteriological test

\section{Introduction}

Brucellosis was a zoonotic infection caused by Brucella resulting in reproductive failure in animals and febrile diseases in humans [1]. Based on sole phenotypic characterization using a range of bacteriological and biochemical tests, Brucella was generally classified into six species including Brucella melitensis, Brucella abortus, Brucella suis, Brucella canis, Brucella ovis and Brucella neotomae, respectively [2]. Over recent years, the number of species has increased to 10 as several new Brucella strains had been isolated from marine mammals, rodents, and infected human breast implant, respectively $[3,4,5]$.

An important characteristic of Brucella was that they could penetrate the endothelial reticulum and infect macrophages, acting as facultative intracellular parasites $[6,7]$. Human being can be infected with Brucellosis through various routes eg consumption of contaminated dairy products, microbial inoculation through cuts or abrasions in the skin surface, the conjunctiva inoculation, inhalation of infectious aerosols, accidental human contact with infected animals and consumption of contaminated meat [8]. The common clinical symptoms included weakness, lethargy, chill, fever, sweating, decreased appetite, arthralgia, myalgia, weight loss, headache, back pain and psychological symptoms [6].

The most important first step for control of the disease was accurate diagnosis of brucellosis [9]. Bacteriological detection of brucellosis in humans was the confirming method and depended on the isolation of the bacteria from blood and bacteriological tests and its biotype, which would take at least one week [10]. Due to the adequate sensitivity, simplicity and lower cost, serological tests such as standard agglutination test (SAT), rose bengal test (RBT) and enzyme-linked immunosorbent assay (ELISA). were commonly used for brucellosis screening in laboratory [11].

Xinjiang, the north-western part of China was one of the areas with high prevalence of brucellosis, Many ethnic groups are intermingled and most people are engaged in agriculture and animal husbandry. Traditional habits, limited veterinary support services and husbandry practices aggravated the spread of this disease. In this study, the incidence of brucellosis in outpatients from Xinjiang region and its correlation with gender, ethnic group and clinical symptoms has been investigated. Moreover, the diagnosis value of serological and bacteriological detection on brucellosis has also been evaluated.

\section{Materials and methods Patients and Samples}

All samples of high-risk individuals $(n=2,648)$ were mainly collected between July 2011 and August 2012 from outpatients at Infectious Disease Hospital of Xinjiang Uygur Autonomous Region, Urumqi, China who were also residents in Xinjiang region. These peoples included the patients $(n=1,243)$ with clinical symptoms suggestive of brucellosis such as fever, sweating, arthralgia, myalgia and weakness and individuals $(n=1,405)$ with intimate contact history with individuals who were infected with brucellosis or their family members are infected with brucellosis. The blood samples were taken by the 
Wu et al. Microbiology Discovery 2013,

http://www.hoajonline.com/journals/pdf/2052-6180-1-2.pdf

doi: $10.7243 / 2052-6180-1-2$

Table 1. Brucellosis distribution on Demographic characteristics and common clinical symptoms.

\begin{tabular}{lccccc}
\hline Parameters & Cases(n) & $\begin{array}{c}\text { Individuals with } \\
\text { non-brucellosis (\%) }\end{array}$ & $\begin{array}{c}\text { Individuals with } \\
\text { brucellosis (\%) }\end{array}$ & $\mathbf{X}^{2}$ & P \\
\hline Age & \multicolumn{7}{l}{ (232(8.8\%) } & $118(4.5 \%)$ & 27.87 & $<0.001$ \\
\hline $0-20$ & 350 & $645(24.4 \%)$ & $384(14.5 \%)$ & - & - \\
$21-40$ & 1029 & $530(20.0 \%)$ & $442(16.7 \%)$ & - & - \\
$41-60$ & 972 & $201(7.6 \%)$ & $96(3.6 \%)$ & - & - \\
61 or older & 297 & $707(26.7 \%)$ & $283(10.7 \%)$ & 75.75 & $<0.001$ \\
\hline Gender & 990 & $901(34.0 \%)$ & $757(28.6 \%)$ & - & - \\
\hline Female & 1658 & & & & \\
Male & 1612 & $1021(38.6 \%)$ & $591(22.3 \%)$ & 11.79 & $<0.01$ \\
\hline Ethnic groups & 1036 & $587(22.2 \%)$ & $449(17.0 \%)$ & - & - \\
\hline Han & 1243 & $520(19.6 \%)$ & $723(27.3 \%)$ & 350.53 & $<0.001$ \\
Ugyur & 1405 & $1088(41.1 \%)$ & $317(12.0 \%)$ & - & - \\
\hline Common clinical symptoms of brucellosis & &
\end{tabular}

qualified nurses or laboratory technicians. Sera were separated and tested within two hours. The brucellosis was diagnosed according to the criterion published by Ministry of Health of the People's Republic of China.

\section{Rose bengal test (RBT)}

The antigen used in the RBT was obtained from the Infectious Disease Institute of Center for Disease Control and Prevention (CDC), Beijing, China. It was prepared and standardized according to the instruction of the manufacturer. Serum samples and antigens were removed from the refrigerator and placed at room temperature for one hour. The test was done by dispensing $0.03 \mathrm{ml}$ of each serum to be tested to an enamel plate. The same amount of Rose Bengal antigen was added to each serum and mixed and shaked by hand for 4 minutes, and the test result was then read. Agglutination appeared as weak positive, positive, strong positive, or very strong positive.

\section{Brucella standard agglutination test (SAT)}

The SAT was carried out by double- dilution of serum from 1:25 to 1:800 according to previous report [12]. Brucella antigen and control sera were used according to the instruction of the manufacturer. Positive reactions were determined using agglutinoscope, and the titre given indicated the highest dilution in which $50 \%$ or more agglutination occurred in the tube.

\section{Culture and identification of organism}

A minimum of $8 \mathrm{ml}$ of blood (for children 1-3 ml) was taken through vein puncture and was injected into the culture vials (Peds plusTM/F for children and Plus Aerobic/F for adults, BD BACTECTM, BD company, USA). And then, the culture vials were loaded to BD BACTECTM/FX Culture System(BD company, USA) and monitored for 7 days before vials with negative results were removed according to the procedures outlined by the Clinical and Laboratory Standards Institute. If a vial shows positive result, a $100-\mu \mathrm{l}$ of blood sample was streaked onto sheep-blood agar plates or Brucella medium plate (Mast Diagnostics, UK). Plates were incubated at $37^{\circ} \mathrm{C}$ aerobically and in the presence of $5-10 \%$ of $\mathrm{CO} 2$. Plates were examined every 3 days for growth. Typical and well-isolated Brucellalike colony is small, transparent, raised, and convex, with an entire edge and smooth and glistening surface along the streak lines by examining macroscopically by Gram's stain. In addition, bacterial suspension was also prepared and adjusted to $0.5 \mathrm{McBurney}$ unit (about $10^{8} \mathrm{cfu} / \mathrm{ml}$ ) with $4.5 \%$ saline for VITEK 2 Gram-Negative Identification Card (VITEK 2 GN Test Kit). The microorganism was identified by the VITEK 2 Identification System (bioMerieux, Inc., France) according to biochemical reactions in the card. The result was reported by the software automatically.

\section{Statistical analysis}

Statistical analysis was performed using Statistical Package for Social Sciences (SPSS) for Windows, version 12.0. The significance of differences between groups was determined using Chi-square. A value of $\mathrm{P} \leq 0.05$ was considered as statistically significant.

\section{Results \\ Demographic findings}

A total of 2,648 individuals of outpatients distributed in seven areas/cities of Xinjiang region, including Urumqi, Yining, Aksu, Hotan, Kaxka, Koria and Turpan were registered. 1080 individuals (40.8\%) were diagnosed as infected with brucellosis with ages ranging from 0 to 89 years old. In the 40-61 years-old group, the infection rate of brucellosis reached $16.7 \%$ (442 individuals) and significant difference was found between various age groups $\left(X^{2}=27.87, P<0.001\right)$. In all suspected cases, the incidence of brucellosis in male, Uygur people and individuals with clinical symptoms was statistically higher than that in female $\left(\mathrm{X}^{2}=75.75, \mathrm{P}<0.001\right)$, people of Han nationality $\left(X^{2}=11.79, P<0.01\right)$ and individuals without clinical symptoms $\left(X^{2}=350.53, P<0.001\right)$, respectively (Table 1).

Multivariate logistic regression analysis of risk factors Multivariate logistic regression analysis suggested that gender [odds ratio (OR) $2.09,95 \% \mathrm{Cl} 1.745-2.503, \mathrm{P}=0.000)$ ], ethnic groups (OR 1.254, 95\% Cl1.055-1.492, $\mathrm{P}=0.01$ ), and clinical symptoms (OR 4.694, 95\% Cl 3.956-5.569, $\mathrm{P}=0.000$ ) were highly associated with positive infection of brucellosis. The results were shown in (Table 2 ).

\section{Serological tests}

The overall distribution of SAT and RBT results found in the surveyed individuals and the percentages of individuals with a SAT or RBT were shown in (Table 3). The percentage of positive titres in SAT $(\geq 50)$ and RBT were $40.8 \%$ and $40.7 \%$, respectively. There was no statistical difference between SAT and RBT $(P>0.05)$. However, the positive rate of SAT 
Wu et al. Microbiology Discovery 2013,

Table 2. Multivariate logistic regression analysis.

\begin{tabular}{lccccc}
\hline Variable & S.E & Wald & P & OR & 95.0\% CI for OR \\
\hline Gender & 092 & 64.161 & .000 & 2.090 & $1.745-2.503$ \\
Ethnic groups & .088 & 6.567 & .010 & 1.254 & $1.055-1.492$ \\
Clinical symptoms & .087 & 314.293 & .000 & 4.694 & $3.956-5.569$ \\
\hline S.E
\end{tabular}

S.E, standard error; OR, odds ratio; 95\% CI, 95\% confidence interval.

Table 3. Prevalence of SAT, BRT and Microbial culture and identification in individuals with and without clinical symptoms of brucellosis.

\begin{tabular}{lcccc}
\hline Test & Result & Cases(n) & $\begin{array}{c}\text { Individuals with } \\
\text { clinical symptoms } \\
\text { of brucellosis (\%) }\end{array}$ & $\begin{array}{c}\text { Individuals } \\
\text { without clinical } \\
\text { symptoms of } \\
\text { brucellosis (\%) }\end{array}$ \\
\hline SAT & Negative & 1568 & $240(9.1 \%)$ & $1328(50.2 \%)$ \\
& $1: 50$ & 225 & $192(7.3 \%)$ & $33(1.3 \%)$ \\
& $1: 100$ & 180 & $145(5.5 \%)$ & $35(1.3 \%)$ \\
& $1: 200$ & 214 & $162(5.5 \%)$ & $52(2.0 \%)$ \\
& $1: 400$ & 396 & $305(11.5 \%)$ & $91(3.4 \%)$ \\
& $1:>400$ & 65 & $48(1.8 \%)$ & $17(0.64 \%)$ \\
& Total positive & 1080 & $852(32.2 \%)$ & $228(8.6 \%)$ \\
\hline RBT & Negative & 1570 & $289(10.9 \%)$ & $1281(48.4 \%)$ \\
Microbial culture & Positive & 1078 & $778(29.4 \%)$ & $300(17.8 \%)$ \\
\hline and identification & Negative & 208 & $35(5.6 \%)$ & $173(27.7 \%)$ \\
& Positive & 416 & $364(58.3 \%)$ & $52(8.3 \%)$ \\
\hline
\end{tabular}

was significantly higher than that of RBT in the group of the individuals without clinical symptoms $\left(X^{2}=12.90, P<0.01\right)$.

\section{Brucella bacteriological detection}

Blood samples of 624 cases were subject to bacteriological examination. The positive samples of blood culture were inoculated onto the plates of sheep-blood agar and Brucella agar selective media. After 3-4 days of inoculation, the colonies with pinpoint, glistening, smooth and translucent appearance were subject to Gram's stain and only gram-negative coccobacilli were sent to further confirmatory tests. The result demonstrated that the total positive rate of blood culture was $66.7 \%(416 / 624)$ (Table 3$)$. The individuals with/without clinical symptoms of brucellosis were 364 (58.3\%) and 52 (8.3\%) from serological test positive samples, respectively (Table 3 ). The positive percentage of individuals with clinical symptoms was significantly more than that of individuals without clinical symptoms $\left(X^{2}=297.3, P<0.001\right)$. What is isolated from blood was identified as Brucella melitensis biotype 3 by the VITEK 2 Identification System.

\section{Discussion}

Brucellosis continues to be a major public and animal health problem in many regions of the world. According to World Health Organization (WHO), every year 500,000 people were infected [13]. In the USA, 4 to $10 \%$ of cases were diagnosed and reported [14,15]. A total of 189,226 cases of human brucellosis were reported officially, about 90,000 of these were registered between 2000 and 2005 (approximately
15,000 cases per year) in Turkey [16]. The prevalence rate of brucellosis in different provinces of Iran varies from 1.5 up to 107.5 per 100,000 persons in 2003 [17]. However, the number of reported patients was only $1 / 25$ to $1 / 10$ of the actual number patients of this disease in the community. There was very little information about the prevalence of brucellosis in China.

It was well known that Xinjiang was located at the middle point of the Silk Road and used to be the traffic route linking Rome to Xi'an, China from ante-Christum, surrounded by Mongolia in the east, Russia in the north, Kazakhstan, Kyrgystan and Tadzhikistan in the west and Pakistan, India, Tibet in the south. In the area, Uygur people were dominant (46.4\% of all population in Xinjiang) and they are mostly engaged in agriculture and animal husbandry, and the direct contact with animals and animal products was common. Taking unpasteurized dairy products was usual. Furthermore, keeping, slaughtering, and taking of dairy and non-dairy products from livestock were carried out traditionally. The main livestock of the region were sheep, goat, and cattle.

Brucellosis was a zoonosis and, with few exceptions, infection in humans resulted from direct or indirect contact with animal sources. The main source of infection for the general population was dairy products prepared from milk from infected livestock. The milk of infected sheep, goats or cattle may contain large numbers of viable organisms, which become concentrated in products such as yogurt, milk tea, cheese, and etc [18]. For good-taste of food, the meat was usually barbecued and half-baked. In this study, the incidence of brucellosis in Uygur people was higher than that in Han people $(\mathrm{P}<0.01)$, and highest in patients aged between 40 and 60 years (16.7\%). It may attribute to different habits between both ethnic groups.

In addition, direct contact with livestock was a well documented source of infection. Infection might occur through cuts and abrasions on the skin, via the conjunctiva, and by inhalation. These routes of infection were quite common for farmers, veterinarians, and butchers, who were all exposed to higher risk of infection through their contact with animals and animal products. In the surveyed outpatients, most of them were engaged in high-risk occupations as described above and the percentage of brucellosis reached $40.8 \%$. The positive rates of male and individuals with clinical symptoms were significantly higher than that of female and those without clinical symptoms $(P<0.001, P<0.001$, respectively). The result was correlative with Uygur tradition that men dominantly worked outside and infection risks increased. Multivariate logistic regression analysis demonstrated that gender, ethnic group, and clinical symptoms were highly associated with positive rate of brucellosis (Table 2).

The brucellosis in human has a diverse range of clinical symptoms, and the most important of them was undulant fever and arthrodynia $[\mathbf{1 9}, \mathbf{2 0}]$. Substantial proportion 
Wu et al. Microbiology Discovery 2013,

of patients were accompanied with splenomegaly and/or hepatomegaly. When the disease became chronic, it would affect almost all organs and resulting in a complicated syndrome including spondylitis, endocarditis, and meningoencephalitis [19]. Antibiotics regimens eg Doxycycline $1 \mathrm{~g}$ twice a day and rifampicin $600 \mathrm{mg}$ daily for 3-6 monthes was usually used in the treatment of acute patients with brucellosis.

The diagnosis of human brucellosis was not difficult if the level of suspicion was high and the symptom was typical, but the varied manifestations for localized, sub-acute, or chronic infection made it prone to be misdiagnosed [21-23]. As the symptoms of brucellosis were non-specific, the diagnosis could be done based upon laboratory finding only [24].

Serological test such as SAT and RBT were useful methods for indirect diagnosis or screening of brucellosis. The positive percentage of SAT and RBT in this study were $40.8 \%$ and $40.7 \%$, respectively (Table 1 ). No significant difference was found between two methods ( $P>0.05)$. However, the Brucella antibodies detected in asymptomatic individuals could be related to a history of exposure, inactive brucellosis, or repeated exposure to antigenic stimuli [25]. The positive percentage of SAT and RBT in individuals without clinical symptoms were $21.1 \%$ and 27.8 $\%$ of positive cases, respectively (Table 3 ). It might reflect that antibody profiles did not have specific clinical correlations, and titers often remained high for a protracted period. Generally, IgM against Brucella would appeare as early as the first week after being infected, followed by an IgG amplification at the second week. Both classes of immunoglobulin peaked during the fourth week and the antibiotics application was accompanied with a decline in both IgM and IgG titers. IgM titers persisted at levels that were higher than those of IgG titers for more than six months, and both classes were persistent for almost one year [25].

The seropositivity of SAT in individuals with clinical symptoms was statistically higher than that of RBT $(P<0.01)$. It may be attributed to the fact that the higher titer of antibody in the individuals with clinical symptoms was double-diluted to proper concentration to antigen in SAT, and avoiding of "hook effect" resulting in immunological reaction which was easy to be observed.

Bacteriological examination was regarded as the "golden standard" method in brucellosis diagnosis, although the bacteriological isolation and identification was a timeconsuming procedure. The initial isolation of bacteria was a big problem in diagnostic laboratories [26]. Fortunately, the professional blood-culture vials and culture system had been applied generally in clinical laboratories, the positive percentage of blood culture has dramatically increased in current years. In the study, the majority of samples subject to blood culture was from patients with high suspicion of brucellosis, who had an epidemiologic history, severer clinical symptoms and/or high titer of antibody in serological test. Total positive rate of bacteriological culture was $66.7 \%(416 / 624)$, reaching $58.3 \%$ in samples of individuals with clinical symptoms, which was significantly higher than that of individuals without clinical symptoms $(\mathrm{P}<0.001)$.

Brucella melitensis, Brucella abortus, and Brucella suis were the three species associated with human disease. In this study, What was isolated were identified as Brucella melitensis biotype 3, which implied sheep or goat as potential source of infection for brucellosis in Xinjiang area of China.

In conclusion, although brucellosis had been, or was close to being eradicated from a number of developed countries, it continued to be a major public and animal health problem in many regions in the developing countries of the world. In Xinjiang area, human cases continued to occur due to their traditional use of raw milk products or eating the half-baked meat and having close contact with infected animals or people. A well developed healthcare system and preventive measures would help to reduce potential infection risks and decrease incidence of brucellosis.

\section{Competing interests}

The authors declare that they have no competing interests.

\section{Acknowledgement}

We thank the Natural Science Foundation (NO. BK2009274) and the Special Fund of Clinical Medicine (NO. BL2012063) from Jiangsu, China for their financial support.

\section{Publication history}

Received: 10-Jan-2013 Revised: 29-Jan-2013

Accepted: 16-Feb-2013 Published: 14-Mar-2013

\section{References}

1. Boschiroli M L, Foulongne $V$ and $O^{\prime}$ Callaghan D: Brucellosis: a worldwide zoonosis. Curr Opin Microbiol 2001, 4:58-64. | Article | PubMed

2. Christopher S, Umapathy B L and Ravikumar K L: Brucellosis: review on the recent trends in pathogenicity and laboratory diagnosis. $J$ Lab Physicians 2010, 2:55-60. | Article | PubMed Abstract | PubMed Full Text

3. Scholz H C, Hubalek Z, Sedlacek I, Vergnaud G, Tomaso H, Al Dahouk S, Melzer F, Kampfer P, Neubauer H, Cloeckaert A, Maquart M, Zygmunt M S, Whatmore A M, Falsen E, Bahn P, Gollner C, Pfeffer M, Huber B, Busse $\mathrm{H} \mathrm{J}$ and Nockler K: Brucella microti sp. nov., isolated from the common vole Microtus arvalis. Int J Syst Evol Microbiol 2008, 58:37582. | Article | PubMed

4. Scholz H C, Nockler K, Gollner C, Bahn P, Vergnaud G, Tomaso H, Al Dahouk S, Kampfer P, Cloeckaert A, Maquart M, Zygmunt M S, Whatmore A M, Pfeffer M, Huber B, Busse H J and De B K: Brucella inopinata sp. nov., isolated from a breast implant infection. Int J Syst Evol Microbiol 2010, 60:801-8. | Article | PubMed

5. Foster G, Osterman B S, Godfroid J, Jacques I and Cloeckaert A: Brucella ceti sp. nov. and Brucella pinnipedialis sp. nov. for Brucella strains with cetaceans and seals as their preferred hosts. Int J Syst Evol Microbiol 2007, 57:2688-93. | Article | PubMed

6. Trujillo IZ, Zavala AN, Caceres JG, Miranda CQ: Brucellosis. Infectious Disease Clinics of North America 1994, 8:225-41.

7. Acosta-Gonzalez R I, Gonzalez-Reyes I and Flores-Gutierrez G H: Prevalence of Brucella abortus antibodies in equines of a tropical region of Mexico. Can J Vet Res 2006, 70:302-4. | PubMed Abstract | PubMed Full Text

8. Fosgate G T, Carpenter T E, Chomel B B, Case J T, DeBess E E and Reilly K F: Time-space clustering of human brucellosis, California, 1973-1992. Emerg Infect Dis 2002, 8:672-8. | Article | PubMed Abstract | PubMed 
Wu et al. Microbiology Discovery 2013,

http://www.hoajonline.com/journals/pdf/2052-6180-1-2.pdf

Full Text

9. Elfaki M G, Al-Hokail A A, Nakeeb S M and Al-Rabiah F A: Evaluation of culture, tube agglutination, and PCR methods for the diagnosis of brucellosis in humans. Med Sci Monit 2005, 11:MT69-74. | Article | PubMed

10. Gee J E, De B K, Levett P N, Whitney A M, Novak R T and Popovic T: Use of $16 \mathrm{~S}$ rRNA gene sequencing for rapid confirmatory identification of Brucella isolates. J Clin Microbiol 2004, 42:3649-54. | Article | PubMed Abstract I PubMed Full Text

11. FAO/WHO-Expert-Committee-on-Brucellosis: World Health Organization technical report series no. 740: 6th report, Geneva. 1986.

12. Young E J: Serologic diagnosis of human brucellosis: analysis of $\mathbf{2 1 4}$ cases by agglutination tests and review of the literature. Rev Infect Dis 1991, 13:359-72. | Article | PubMed

13. World-Organisation-or-Animal-Health. Handistatus II: zoonoses (human cases): global cases of brucellosis in 2003.

14. Monajjemi M, Moniri E, Panahi HA: Thermodynamic studies on complexation of glutamic acid with dioxovanadium(V) in mixed solvent systems. Journal of Chemical and Engineering Data 2001,46:1249-54. | Article

15. MM M, DL K. Brucellosis. 15 ed. McGraw Hill Medical Publishing division, 2001

16. Yumuk Z and O'Callaghan D: Brucellosis in Turkey -- an overview. Int J Infect Dis 2012, 16:e228-35. | Article | PubMed

17. Rezaee MA, Rashidi A, Motaharinia Y, Hossaini W, Rahmani MR: Seroprevalence study of brucellosis among high-risk groups in comparison with other people of the population in Sanandaj (West of Iran). African Journal of Microbiology Research 2012, 6:5.

18. Ongor H, Cetinkaya B, Karahan M and Bulut H: Evaluation of immunomagnetic separation-polymerase chain reaction in direct detection of Brucella abortus and Brucella melitensis from cheese samples. Foodborne Pathog Dis 2006, 3:245-50. | Article | PubMed

19. Pappas G, Akritidis N, Tsianos EV: Brucellosis - Reply. New England Journal of Medicine 2005, 353:1072.

20. Franco M P, Mulder M, Gilman R H and Smits H L: Human brucellosis. Lancet Infect Dis 2007, 7:775-86. | Article | PubMed

21. Corbel M J: Recent advances in brucellosis. J Med Microbiol 1997, 46:101-3. | Article | PubMed

22. Young D A: Florence Nightingale's fever. BMJ 1995, 311:1697-700. | Article | PubMed Abstract | PubMed Full Text

23. Young E J: An overview of human brucellosis. Clin Infect Dis 1995, 21:283-9; quiz 290. | Article | PubMed

24. Leyla G, Kadri G and Umran O: Comparison of polymerase chain reaction and bacteriological culture for the diagnosis of sheep brucellosis using aborted fetus samples. Vet Microbiol 2003, 93:53-61. I Article | PubMed

25. Ariza J, Pellicer T, Pallares R, Foz A and Gudiol F: Specific antibody profile in human brucellosis. Clin Infect Dis 1992, 14:131-40. | Article | PubMed

26. Leal-Klevezas D S, Martinez-Vazquez I O, Lopez-Merino A and MartinezSoriano J P: Single-step PCR for detection of Brucella spp. from blood and milk of infected animals. J Clin Microbiol 1995, 33:3087-90. | Article | PubMed Abstract | PubMed Full Text

\section{Citation:}

Wu G, Yang C, Li j, Liu N, Yao W, Zhang R and Lin Z:

Prevalence study of brucellosis among high-risk people in xinjiang region, China. Microbiology Discovery 2013, 1:2. http://dx.doi.org/10.7243/2052-6180-1-2 